\title{
Construindo o saber a partir de práticas demonstrativas biológicas no processo de ensino-aprendizagem
}

\author{
Priscila Beleza Cruz \\ Discente do Curso de Ciências: Biologia e Química, Instituto de Educação, Agricultura e Ambiente (IEAA), \\ Universidade Federal do Amazonas (UFAM) \\ $\triangle$ pri.beleza44@gmail.com \\ Viviane Guedes de Oliveira \\ Docente do Curso de Ciências: Biologia e Química - IEAA/UFAM \\ ه oliveiravg@hotmail.com \\ Jorge Almeida de Menezes \\ Docente do Curso de Ciências: Biologia e Química - IEAA/UFAM \\ $\triangle$ jorgejr@ufam.edu.br \\ Renato Abreu Lima \\ Docente do Curso de Ciências: Biologia e Química - IEAA/UFAM \\ $\bowtie$ renatoal@ufam.edu.br
}

\begin{abstract}
Resumo:
As feiras de Ciências são ferramentas relevantes no processo ensino-aprendizagem do aluno, pois possibilitam a compreensão de conceitos estudados em sala de aula através de demonstrações experimentais, no qual, através do ensino de ciências possibilita uma relação do conhecimento cotidiano com o conhecimento científico, além de favorecer uma contextualização e a interdisciplinaridade. Deste modo, o presente artigo tem como objetivo demonstrar experimentos biológicos envolvendo a contextualização e a interdisciplinaridade da feira de Ciências na Escola Estadual Plínio Ramos Coelho. Para atender ao objetivo do projeto, executou-se a feira de ciências no evento intitulado "III Amostra do Saber", onde se encontrava nove bolsistas do PIBID da Instituição de Educação, Agriculta e Ambiente - IEAA/UFAM. Estes foram divididos em três duplas e um trio, onde ficaram responsáveis em confeccionar um experimento demonstrativo da área da biologia, totalizando quatro experimentos, no qual tinha como propósito contribuir no processo ensinoaprendizagem dos alunos e sociedade presente no evento, além de envolver a contextualização da cientificidade com o cotidiano. Com isto, obtiveram-se resultados satisfatórios, pois os bolsistas do PIBID, alunos da escola e comunidade trocaram experiências por meio dos experimentos realizados na feira de ciências, proporcionando conhecimento para todos os participantes. Por fim, conclui-se que por meio do projeto realizado é possível relacionar e compreender conteúdos vistos anteriormente em sala de aula por meio de demonstrações biológicas.

Palavras-chave: Experimentos científicos, Feira de ciências, PIBID, Ensino, Biologia.
\end{abstract}

\section{Building knowledge from biological demonstrative practices in the teaching-learning process}

\begin{abstract}
:
Science fairs are relevant tools in the student's teaching-learning process, as they enable the understanding of concepts studied in the classroom through experimental demonstrations, in which,
\end{abstract}


through science teaching, it enables a relationship between everyday knowledge and scientific knowledge, besides favoring contextualization and interdisciplinarity. Thus, this article aims to demonstrate biological experiments involving the contextualization and interdisciplinarity of the science fair at the Plínio Ramos Coelho State School. To meet the project's objective, the science fair was held at the event entitled "III Sample of Knowledge", where nine PIBID scholarship holders from the Institution of Education, Agriculture and Environment - IEAA / UFAM were located. These were divided into three pairs and a trio, where they were responsible for making a demonstration experiment in the area of biology, totaling four experiments, in which it was intended to contribute to the teaching-learning process of students and society present at the event, in addition to involving the contextualization of scientificity with everyday life. With this, satisfactory results were obtained, as the PIBID scholarship holders, students from the school and the community exchanged experiences through the experiments carried out at the science fair, providing knowledge for all participants. Finally, it is concluded that through the project carried out it is possible to relate and understand content previously seen in the classroom through biological demonstrations.

Keywords: Scientific experiments, Science fair, PIBID, Teaching, Biology.

\title{
Desarrollar conocimiento a partir de prácticas demostrativas biológicas en el proceso de enseñanza-aprendizaje
}

\begin{abstract}
Resumen:
Las ferias de ciencias son herramientas relevantes en el proceso de enseñanza-aprendizaje del estudiante, ya que permiten la comprensión de los conceptos estudiados en el aula a través de demostraciones experimentales, en las cuales, a través de la enseñanza de las ciencias, permite una relación entre el conocimiento cotidiano y el conocimiento científico, además de favorecer la contextualización y la interdisciplinariedad. Por lo tanto, este artículo tiene como objetivo demostrar experimentos biológicos que involucran la contextualización e interdisciplinariedad de la feria de ciencias en la Escuela Estatal Plínio Ramos Coelho. Para cumplir con el objetivo del proyecto, la feria de ciencias se llevó a cabo en el evento titulado "III Muestra de Conocimiento", donde se ubicaron nueve becarios PIBID de la Institución de Educación, Agricultura y Medio Ambiente - IEAA / UFAM. Estos se dividieron en tres pares y un trío, donde se encargaron de realizar un experimento de demostración en el área de biología, con un total de cuatro experimentos, en los que se pretendía contribuir al proceso de enseñanza-aprendizaje de los estudiantes y la sociedad presentes en el evento, además de involucrar al contextualización de la cientificidad con la vida cotidiana. Con esto, se obtuvieron resultados satisfactorios, ya que los becarios PIBID, los estudiantes de la escuela y la comunidad intercambiaron experiencias a través de los experimentos llevados a cabo en la feria de ciencias, brindando conocimiento a todos los participantes. Finalmente, se concluye que a través del proyecto llevado a cabo es posible relacionar y comprender el contenido previamente visto en el aula a través de demostraciones biológicas.
\end{abstract}

Palabras clave: Experimentos científicos, feria de ciencias, PIBID, enseñanza, biología.

\section{INTRODUÇÃO}

O ensino de Ciências possibilita uma relação do conhecimento cotidiano ao conhecimento científico, além de ocorrer uma contextualização e a interdisciplinaridade, o mesmo se refere às feiras de Ciências, onde estas permitem a prática das teorias estudadas dentro da sala de aula. Assim, a problemática da presente pesquisa deu-se a partir de demonstrações biológicas realizadas durante o processo de aprendizagem, onde se 
demonstrou ser proveitosas no âmbito escolar, ajudando na formação de ensinoaprendizagem do estudante, envolvendo a contextualização do conhecimento comum e conhecimento científico.

As feiras de Ciências atualmente são realizadas como métodos que ajudam na formação dos estudantes, explorando os seus conhecimentos e aprendizados das ciências, expondo trabalhos e experimentos demonstrativos de uma lei científica ou teoria, estimulando o aluno a contextualizar e estimular a investigação e soluções de problemas (VASCONCELOS; FRANCISCA, 2015).

Devido à grande chamativa do evento "Feira de Ciências", as demonstrações tornaram-se mais atrativas e interessantes para os alunos, levando os mesmos na forma prazerosa em aprender e aplicar Ciência de diversas formas. $O$ ato de expor o conhecimento faz com que os estudantes queiram de fato entender para transmitir o conhecimento e ativar seu desempenho criativo, pois o mais diferente é o que atrai este público fazendo este buscar coisas novas e conhecimentos modernos.

Este processo estimula também o trabalho em grupo e valorização do conhecimento já explanado durante o ano, uma vez que a aluno se faz uma retrospectiva do que lhe já foi ensinado, ou algum tópico que, mais lhe chamou atenção para passar de forma diferenciada o conhecimento adiante. 0 trabalho da feira então, se torna grande, rico e diverso, uma vez que não alcança somente o público que estuda diariamente no âmbito escolar, mas toda a população envolvida. Pois de acordo com Machado et al. (2014), a feira de Ciências "assume um importante papel social incentivando a própria cultura à investigação; o desenvolvimento de competências como liderança e trabalho em equipe; a inovação e o empreendedorismo na região".

Tendo o método prático de investigação científica, os alunos tornam-se cientistas temporários, onde por sua vez apresentam seus experimentos e ficam sujeitos a perguntas, questionamentos e curiosidades durante o processo de apresentação. Além disso, as feiras se tornam o ambiente mais propicio de apresentar um meio para descobrir um futuro investigador, pesquisador, cientista ou outro indivíduo da área das Ciências.

Uma vez que escola preza e pensa nos saberes científicos dos alunos, faz o seu conhecimento sair do abstrato para algo mais maciço e palpável, trazendo a ciência para seu 
dia a dia e tornando essa descoberta pessoal de cada estudante a partir do seu contato com a amostragem que é a feira cientifica, pois assim traz Freire (1987), "a proposta se fundamenta no pensar crítico da realidade, afinal o diálogo em aula se fundamenta numa situação pedagógica, refletido, planejado e organizado no ensino [...] que não pode ser imposto, mas sim problematizado, tendo em vista a transformação".

O Programa Institucional de Bolsa de Iniciação à Docência (PIBID) é um dos meios em que os universitários podem ajudar o professor, tendo uma articulação entre a educação superior, a escola e os sistemas estaduais e municipais. Desta forma, detectou-se durante o processo de iniciação à docência o efeito positivo das práticas e experimentos relacionados à biologia. Obteve-se desta forma, uma alta valorização dos alunos na utilização desta metodologia, onde se manifestou grande interesse nos bolsistas do PIBID no desenvolvimento de um trabalho relacionado à exposição de práticas laboratoriais relacionadas às disciplinas de estudo referentes à nossa graduação.

Contribuindo no processo de ensino-aprendizagem dos alunos da escola foram elaborados quatros experimentos científicos, sendo estes da área biológica, onde foram expostos na "III Mostra do Saber" da Escola Estadual Plínio Ramos Coelho, com objetivo de demonstrar os experimentos envolvendo a contextualização e a interdisciplinaridade.

\section{METODOLOGIA}

O presente projeto foi realizado no período da feira de Ciências da Escola Estadual Plinio Ramos Coelho em 2019, na III Mostra do Saber, onde se encontrava nove bolsistas do PIBID da Instituição de Educação, Agriculta e Ambiente - IEAA/UFAM. Estes foram divididos em três duplas e um trio, que ficaram responsáveis em confeccionar um experimento demonstrativo da área de biologia, totalizando quatro experimentos, com intuito de contribuir no processo ensino-aprendizado dos alunos e a sociedade presente no evento, além de envolver a contextualização da cientificidade com o cotidiano.

Cada grupo escolheu um assunto para estudar, compreender e aprender uma teoria ou lei cientifica, tal que esta lei/teoria deveria envolver a contextualização e a 
interdisciplinaridade. Com a escolha do conteúdo os grupos foram destinados a ver materiais de baixo custo que seriam utilizados para fazer a demonstração biológica, sendo estas: Extração do DNA da Banana, Extração do DNA do tomate, Construção do sistema respiratório e Vela de laranja, no qual foram realizadas e apresentadas na III Mostra do Saber.

Ao longo das demonstrações, as pessoas que observavam todos os experimentos receberam um questionário quantitativo para assim observar o quanto que a pessoa se interessou pelas demonstrações, de modo a averiguar a relação dos experimentos com os conteúdos estudados dentro de sala de aula. Além disso, cada autor das demonstrações contextualizava e usava a interdisciplinaridade para assim também fazerem trocas de conhecimentos entre o autor e a plateia presente.

Junto com a demonstração dos experimentos foi realizado 17 questionários, distribuídos entre os estudantes da escola e a comunidade presente, com três perguntas: "1ํ․ Qual o experimento que você mais gostou?", nessa questão foram colocados todos os nomes dos experimentos, no qual o participante deveria marcar qual gostou; " 2 ". Você conseguiu relacionar os experimentos com algum conteúdo estudado dentro da sala de aula? Se sim quais?", nessa pergunta foram colocados também os nomes dos experimentos, tal que marcava experimentos que relacionava com algum conteúdo estudado; "3‥ Os experimentos científicos ajudaram na sua formação?", nessa questão a pessoa teria que dissertar em que os experimentos poderiam ajudar na construção do conhecimento científico, a fim de observar a contextualização entre o meio científico e o popular.

\section{RESULTADOS E DISCUSSÃO}

De acordo com Santos (2012), podem-se compreender as feiras de ciência como eventos sociais, científicos e culturais realizados nas escolas ou na comunidade com a intenção de que durante a apresentação dos estudantes, os mesmos possam oportunizar um diálogo com os visitantes, constituindo-se na oportunidade de discussão sobre os conhecimentos, metodologias de pesquisa e criatividade dos alunos em todos os aspectos referentes à exibição de trabalhos. 
Dentro dessa perspectiva, as feiras de ciência despertam a curiosidade e o interesse, mostram-se como agente motivador e desafiador e permitem o desenvolvimento intelectual e científico, como afirma Mezzari (2011):

o trabalho com feiras desperta a curiosidade e o interesse, principalmente quando utilizam materiais diferentes. Além disso, a própria prática é motivadora. Embalado por esse desafio de experimentar, o aluno ainda desperta seu desenvolvimento intelectual, ao mesmo tempo em que se esforça para pensar e resolver problemas, na busca incessante por resultados. E finalmente, o saber cotidiano passa a ser alvo de confronto. $O$ aluno começa a ter novos posicionamentos diante dos experimentos e de seus resultados, adquirindo um saber mais científico (MEZZARI, 2011).

Neste sentido, o PIBID desenvolvido na Escola Estadual Plínio Ramos Coelho mostra o quanto é relevante para os futuros professores e, sobretudo, para a educação pública a implementação deste na efetiva formação dos futuros educadores, também como importante mecanismo de melhoria da qualidade do processo ensino-aprendizagem no ambiente escolar.

Ao debater a relevância do PIBID na escola Pública, Barros (2013) traz contribuições importantes, onde afirma que:

Dentro do que foi exposto e analisando sobre a atuação do PIBID dentro do espaço escolar que se torna um programa propiciador de saberes e práticas de ensino voltadas para reflexão-ação-reflexão que tem como objetivo principal o aluno e sua aprendizagem. Portando a contribuição do programa de iniciação à docência traz consigo uma contribuição significativa na aprendizagem e no dia a dia dos alunos da escola (BARROS, 2013).

Umas das maiores dificuldades enfrentadas na escola pública é a falta de interesse na aula pelos discentes, eles na maioria das vezes enxergam a aula por monótona e rotineira, e o PIBID entra com a possibilidade de contribuição para auxiliar as aulas de biologia a fim de despertar a curiosidade e o interesse pela pesquisa. Com efeito, de acordo com Barros (2013), o trabalho desenvolvido pelo PIBID não sana as deficiências encontradas nas escolas da rede pública, tampouco supre as necessidades dos alunos contemplados, todavia, a gama de saberes e a forma inovadora como são aplicados através do programa, o torna como ferramenta importantíssima, sobretudo focalizada nas dificuldades e no contexto social desses alunos. 
Diante disso, os experimentos realizados pelos bolsistas na III Mostra do Saber (Quadro 1) foram de grande relevância na aproximação entre universidade e escola, no qual estabeleceu condições adequadas à inserção dos professores em formação no ambiente escolar. Deste modo, despertou-se a curiosidade científica nos estudantes quanto à utilização de métodos que o estimulem a formular questões científicas baseadas na realidade cotidiana por eles vivenciada, despertando assim um maior interesse pela escola, com a elevação da frequência às aulas e melhoria da aprendizagem.

Quadro 1 - Experimentos apresentados na III Mostra do Saber pelos bolsistas

\begin{tabular}{|c|c|c|c|}
\hline Experimento & Conteúdo & Materiais & Procedimentos/Resultados \\
\hline $\begin{array}{c}\text { Extração do } \\
\text { DNA da } \\
\text { Banana }\end{array}$ & DNA Vegetal & $\begin{array}{l}\text { - } \text { Banana madura } \\
\text { - Saco plástico } \\
\text { - Copo de vidro } \\
\text { transparente } \\
\text { - Colher } \\
\text { - Coador } \\
\text { - Álcool } 90^{\circ} \text { gelado } \\
\text { - Tubo de ensaio } \\
\text { - Detergente incolor } \\
\text { - Sal } \\
\text { - Água }\end{array}$ & $\begin{array}{l}\text { Primeiramente amassou-se a } \\
\text { banana dentro do saco plástico } \\
\text { até obter-se uma mistura } \\
\text { homogênea. Após, em um copo } \\
\text { de vidro transparente com } \\
\text { água colocou-se uma colher de } \\
\text { sal misturando-se bem, em } \\
\text { seguida, colocou-se uma colher } \\
\text { de detergente incolor, após } \\
\text { colocou-se a banana amassada } \\
\text { e em seguida misturou-se. } \\
\text { Posteriormente, coou-se a } \\
\text { mistura, em seguida, } \\
\text { transferiu-se a mistura para o } \\
\text { tubo de ensaio, onde se colocou } \\
\text { oálcool cuidadosamente. Desde } \\
\text { modo, com este experimento, } \\
\text { podem-se observar moléculas } \\
\text { de DNA da banana flutuando } \\
\text { dentro de um recipiente. }\end{array}$ \\
\hline
\end{tabular}




\begin{tabular}{|c|c|c|c|}
\hline $\begin{array}{l}\text { Extração do } \\
\text { DNA do tomate }\end{array}$ & DNA Vegetal & $\begin{array}{l}\text { - Tomate } \\
\text { - Saco plástico } \\
\text { - Copo de vidro } \\
\text { transparente } \\
\text { - Colher } \\
\text { - Coador } \\
\text { - Álcool 90º gelado } \\
\text { - Tubo de ensaio } \\
\text { - Detergente incolor } \\
\text { - Sal } \\
\text { - Água }\end{array}$ & $\begin{array}{l}\text { Inicialmente amassou-se o } \\
\text { tomate dentro do saco plástico } \\
\text { até obter-se uma mistura } \\
\text { homogênea. Após, em um copo } \\
\text { de vidro transparente com } \\
\text { água colocou-se uma colher de } \\
\text { sal misturando-se bem, em } \\
\text { seguida, colocou-se uma colher } \\
\text { de detergente incolor, após } \\
\text { colocou-se o tomate amassado } \\
\text { e em seguida misturou-se. } \\
\text { Posteriormente, coou-se a } \\
\text { mistura, } \\
\text { transferiu-se a mistura para o } \\
\text { tubo de ensaio, onde se colocou } \\
\text { o álcool cuidadosamente. Desde } \\
\text { modo, com este experimento, } \\
\text { podem-se observar moléculas } \\
\text { de DNA do tomate flutuando } \\
\text { dentro de um recipiente. }\end{array}$ \\
\hline $\begin{array}{l}\text { Construção do } \\
\text { sistema } \\
\text { respiratório }\end{array}$ & $\begin{array}{c}\text { Sistema } \\
\text { respiratório }\end{array}$ & $\begin{array}{l}\text { - } \text { Garrafa pet } \\
\text { - Tesoura } \\
\text { - Três balões } \\
\text { - } \text { Fita } \\
\text { - Mangueira } \\
\text { - Estilete } \\
\text { - Tinta } \\
\text { - } \text { Pincel } \\
\text { - Uma folha de isopor } \\
\text { - Etiqueta }\end{array}$ & $\begin{array}{l}\text { Primeiramente cortou-se uma } \\
\text { garrafa pet ao meio, em } \\
\text { seguida, colocou-se um pedaço } \\
\text { de fita na parte abaxial da } \\
\text { garrafa, após cortou-se um dos } \\
\text { balões de modo que ficasse } \\
\text { encaixado na parte abaxial da } \\
\text { garrafa. } \\
\text { cortaram-se dois pedaços } \\
\text { pequenos de mangueira, onde } \\
\text { se colocou um balão em cada }\end{array}$ \\
\hline
\end{tabular}




\begin{tabular}{|c|c|c|c|}
\hline & & & $\begin{array}{l}\text { pedaço, após colou-se ambas as } \\
\text { partes deixando apenas um } \\
\text { orifício na parte superior para } \\
\text { que em seguida fosse colocado } \\
\text { mais um pedaço de mangueira } \\
\text { de maior comprimento, e assim } \\
\text { se fez. Em seguida, encaixou-se } \\
\text { o pedaço de mangueira com os } \\
\text { balões na superfície de baixo da } \\
\text { garrafa pet. Por fim, fechou-se } \\
\text { a parte de abaxial da garrafa } \\
\text { pet com o balão cortado } \\
\text { inicialmente. Deste modo, } \\
\text { pode-se observar com este } \\
\text { experimento como funcionam } \\
\text { os órgãos do sistema } \\
\text { respiratório, demostrando } \\
\text { assim cada } \\
\text { ilustrativamente. Para uma } \\
\text { melhor também os } \\
\text { desenharam-se tamão, } \\
\text { órgãos em uma folha de isopor, } \\
\text { para melhor ilustração. }\end{array}$ \\
\hline Vela de laranja & Capilaridade & $\begin{array}{l}\text { - Laranja } \\
\text { - Óleo de cozinha } \\
\text { - Faca } \\
\text { - Tesoura } \\
\text { - Pavio isqueiro }\end{array}$ & $\begin{array}{l}\text { Inicialmente, cortou-se a } \\
\text { laranja ao meio de modo a } \\
\text { retirar apenas a casca, após } \\
\text { retirou-se o bagaço da laranja } \\
\text { deixando-se apenas o miolo. } \\
\text { Em seguida, colocou-se um } \\
\text { pouco de óleo de cozinha na } \\
\text { laranja, após acendeu-se a } \\
\text { mesma como pavio de isqueiro. }\end{array}$ \\
\hline
\end{tabular}




\begin{tabular}{|l|l|l|}
\hline & & $\begin{array}{l}\text { Desde modo, este experimento } \\
\text { tem uma associação às } \\
\text { lamparinas. }\end{array}$ \\
\hline
\end{tabular}

Fonte: Autoria própria

Diante do exposto, os resultados obtidos com as demonstrações biológicas foram satisfatórios, pois os bolsistas do PIBID, alunos da escola e comunidade em geral, observadas na figura 1, trocaram experiências por meio dos experimentos realizados na feira de Ciências, proporcionando assim mais conhecimento para todos os participantes.

Figura 1. População presente na III Mostra do Saber

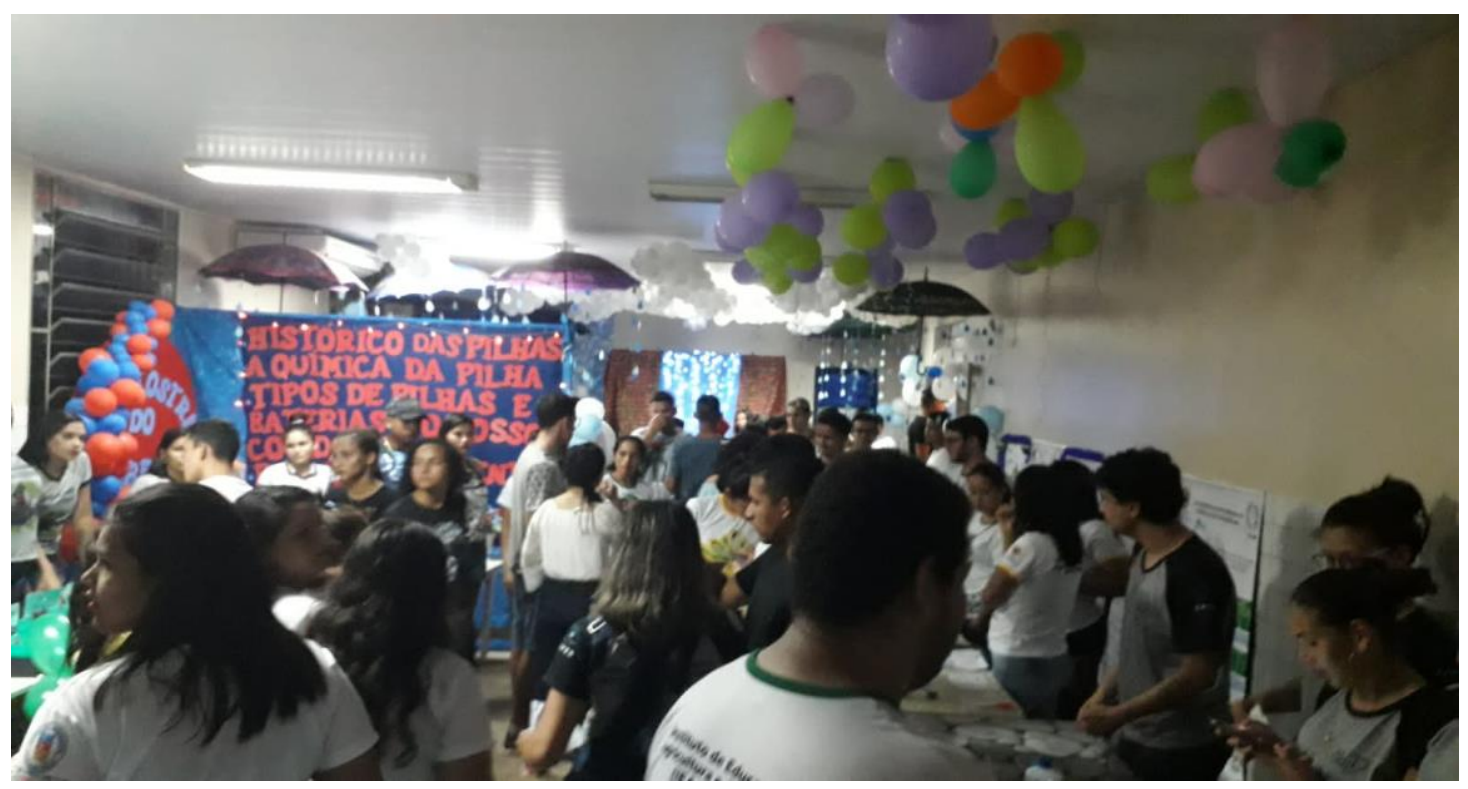

Fonte: Autoria própria.

$\mathrm{O}$ ato de educar pela pesquisa pode desempenhar um papel importante no processo de ensino-aprendizagem, uma vez que é capaz de ajudar a superar a racionalidade técnica, em que cada participante parte de suas próprias teorias, reconstruindo-as e utilizando-as para solucionar problemas emergentes, desenvolvendo uma autonomia, argumentação crítica, a sua linguagem científica, capacidade de falar oralmente e constituição de habilidades, o que torna os alunos sujeitos ativos do processo de aprendizagem. Logo, 
segundo Mezzari (2011), a feira de ciências deve ser encarada como uma metodologia de ensino importante para desenvolver sujeitos críticos e autônomos.

Partindo desta perspectiva, podemos dizer que o PIBID de biologia proporciona aos bolsistas a capacidade de analisar que para ser um bom educador não é necessário apenas o domínio das técnicas, mas, compreender a complexidade do processo de ensinoaprendizagem, que requer dedicação, investimento pessoal e uma busca constante e dinâmica para que ocorra uma transposição didática, oriunda da vivência dessa prática.

Com a aplicação dos 17 questionários, onde participaram do mesmo nove pessoas do gênero feminino, seis do masculino e duas pessoas não se identificaram, como demostrado no gráfico 1, obteve-se resultados satisfatórios, no qual podemos identificar concepções e saberes enriquecedores no processo de ensino-aprendizagem.

Gráfico 1 - Representação gráfica dos gêneros dos participantes da pesquisa

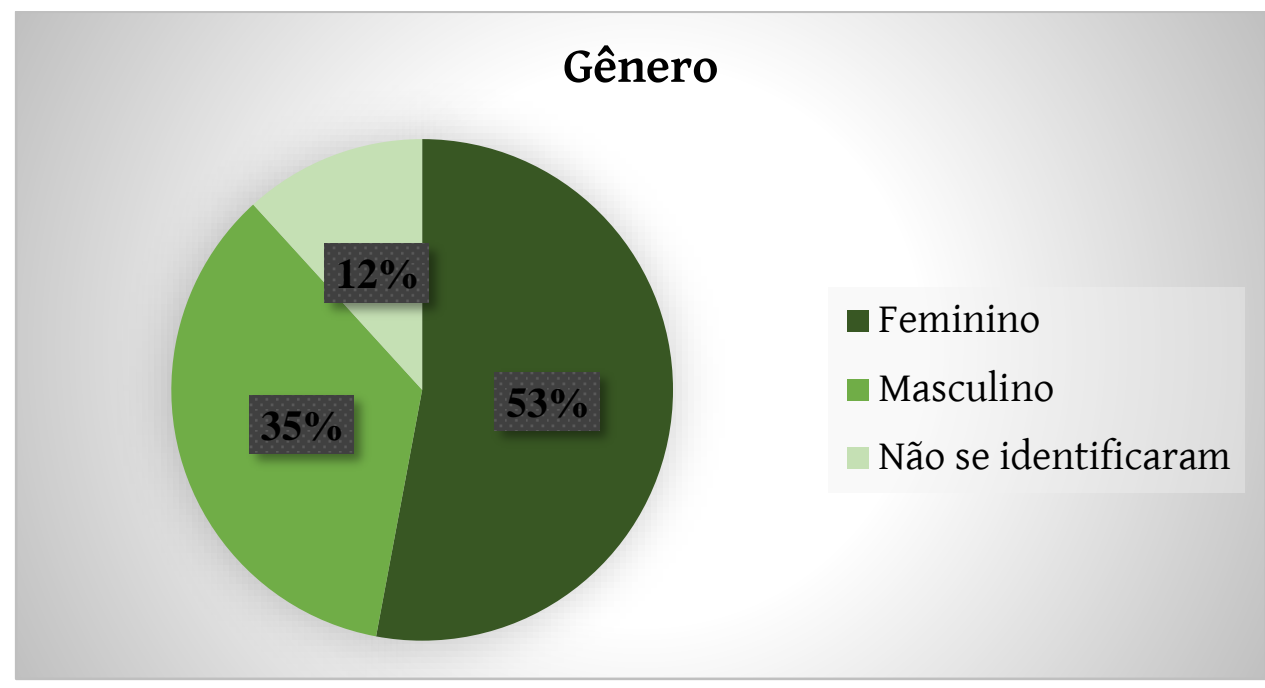

Fonte: Autoria própria.

Em termos de porcentagem, como apresentado no gráfico acima, podemos observar que o gênero feminino teve maior participação na feira de Ciências, porém o masculino também teve uma participação satisfatória. Todavia, não significa que houve uma grande diferença, pois os que não se identificaram podem ser de um gênero ou de outro.

Ao aproximar a universidade e a escola básica pública e reunir professores coordenadores, supervisores e alunos bolsistas, permite com que ocorra uma mobilização no 
processo de formação, onde o programa possibilita aos licenciandos vivenciar a docência compartilhada com os professores das escolas e, ao mesmo tempo, colaborar com o desenvolvimento do processo de ensino-aprendizagem dos alunos.

Sendo assim, podemos dizer que interdisciplinaridade está interligada ao saber útil, onde utiliza conhecimentos de várias disciplinas para a compreensão de uma situação problema, é uma integração de saberes. Em um texto de biologia, por exemplo, além do conhecimento específico da matéria, o aluno pode aprender gramática, elaborar problemas relativos ao texto e muito mais.

Com efeito, na primeira questão do questionário, tivemos como pergunta, "Qual o experimento você mais gostou?", onde se obteve o seguinte resultado (Gráfico 2).

Gráfico 2 - Representação gráfica dos experimentos que os participantes mais gostaram

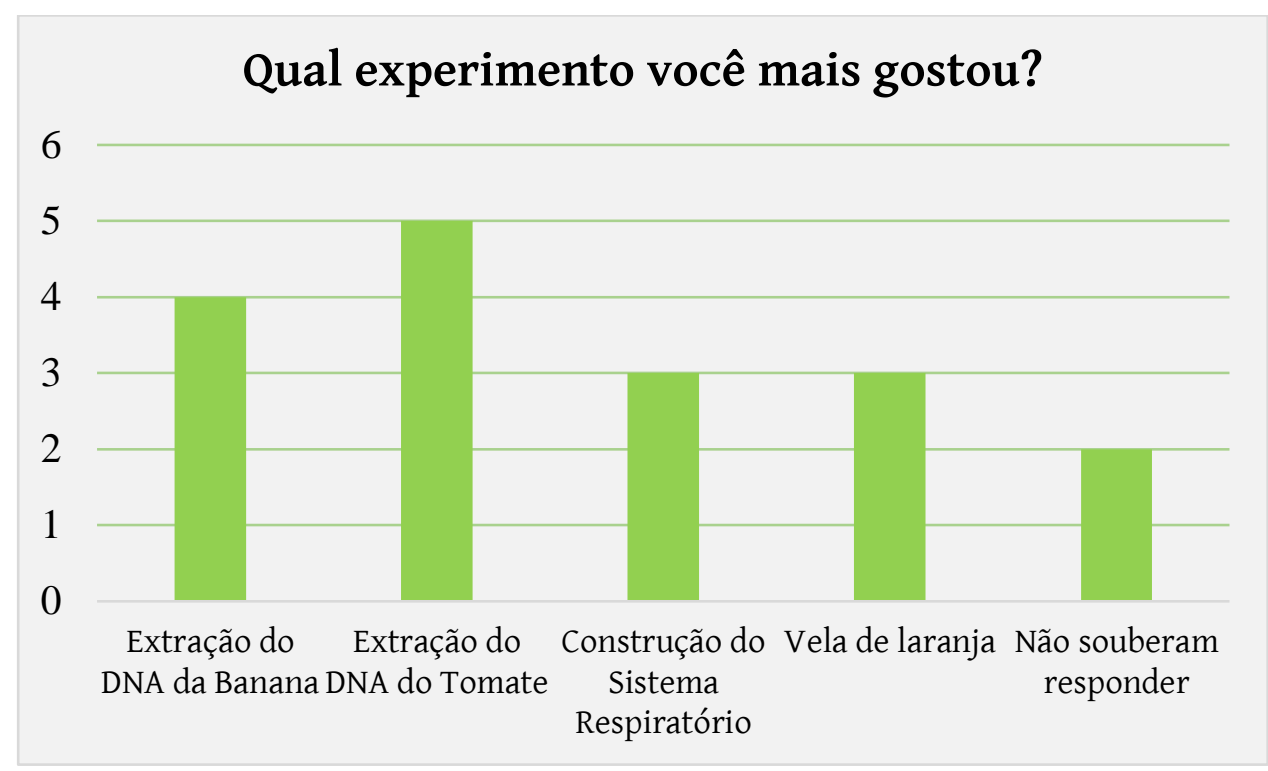

Fonte: Autoria própria.

Tendo o PIBID como promovedor da aproximação entre a universidade e a escola, onde essa parceria tem apontado para a constituição de espaços privilegiados de formação. A universidade, como mostra a pesquisa de Felício (2014) tem se beneficiado dessa aproximação com a escola, pois os licenciandos levam suas experiências de iniciação à docência para a sala 
de aula e revelam uma aprendizagem real ao relacionar teoria com a prática e evidenciarem conhecimentos didáticos pedagógicos necessários a uma atuação competente na escola.

Desde modo, como se pode perceber por meio do gráfico 2, as apresentações dos experimentos foram bem-sucedidas na III Mostra do Saber, pois em todos teve-se participação de pessoas acompanhando o desenvolvimento das práticas e interagindo com os estagiários, com isso o gráfico demonstra que os visitantes gostaram mais do experimento extração do DNA do tomate. Talvez esta tenha sido a escolha dos participantes pelo fato deste experimento (figura 2) chamar mais a atenção dos visitantes, devido à circunstância do mesmo possibilitar por intermédio desde experimento a visualização do DNA do tomate a olho nu, de modo a aplicar os conceitos aprendidos em sala de aula, permitindo a visualização da destruição da parede celulósica que envolve a célula vegetal, além do rompimento da membrana citoplasmática e da liberação do DNA.

Figura 2. Demonstração do experimento de extração do DNA do tomate

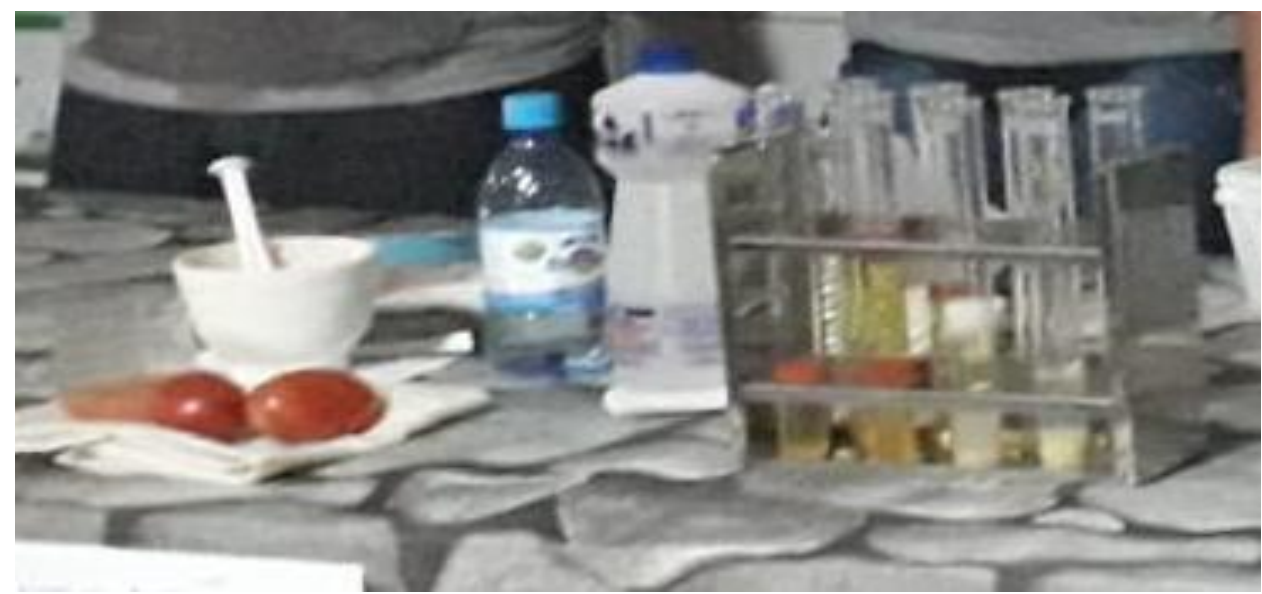

Fonte: Autoria própria.

Segundo estudo realizado por Cavalcante et al. (2018) ao fazer a extração de DNA da babosa (Aloe vera L.) verificaram que a prática é fundamental para que os alunos consigam entender, interpretar e tirar suas próprias conclusões de determinados experimentos. Diante da Biodiversidade Brasileira, espécies vegetais estão sendo utilizadas em aulas práticas para facilitar a compreensão do conteúdo de forma contextualizada. 
O PIBID tem como propósito resgatar o interesse pelas licenciaturas e permitir que através deste programa o licenciando possa ter uma melhor preparação através de suas experiências e vivências em sala de aula, contribuindo assim para que este profissional ao assumir uma sala de aula possa saber lidar com as diversas situações encontradas. Assim, o intuito do PIBID é proporcionar aos discentes de cursos de licenciatura uma aproximação prática com o cotidiano das escolas públicas de educação básica e com o contexto em que elas estão inseridas (BRAGA et al., 2021).

Sendo assim, na segunda questão do questionário, tivemos como pergunta, "Você conseguiu relacionar os experimentos com algum conteúdo estudado dentro da sala de aula? Se sim, quais?". Nesta questão, obtivemos os seguintes resultados, conforme mostra o gráfico 3.

Gráfico 3 - Relação dos experimentos realizados com os conteúdos estudados

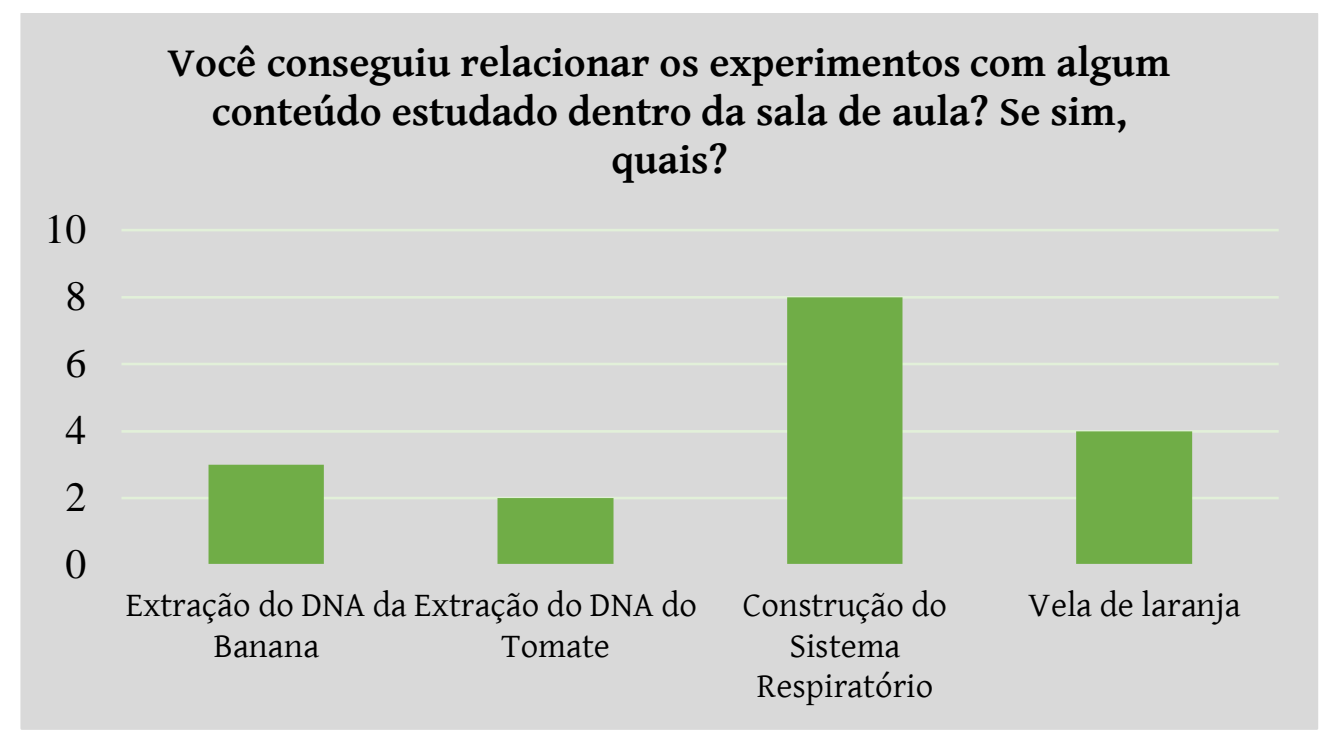

Fonte: Autoria própria.

Neste gráfico, pode-se observar que se destacou a construção do sistema respiratório (Figura 3), pois sendo este um tema associado à anatomia humana acredita-se que o mesmo foi de fácil assimilação. Essa pergunta foi de grande relevância, pois assim é possível relacionar os conteúdos que os alunos estudaram em sala de aula, com os temas trabalhados nas práticas. 
Temos que ter em mente que todas as disciplinas andam de mãos dadas, uma necessita da outra para o seu desenvolvimento. Em biologia, no conteúdo de genética no ensino médio temos que ter conhecimentos em porcentagens e probabilidades onde entra a disciplina de matemática, assim como em geografia para elaborarmos mapas, gráficos e tabelas tem-se que ter conhecimentos matemáticos para trabalhar com escalas, sistemas de medidas, conhecimentos em porcentagens para saber interpretar tabelas e gráficos.

Figura 3. Representação do Sistema Respiratório

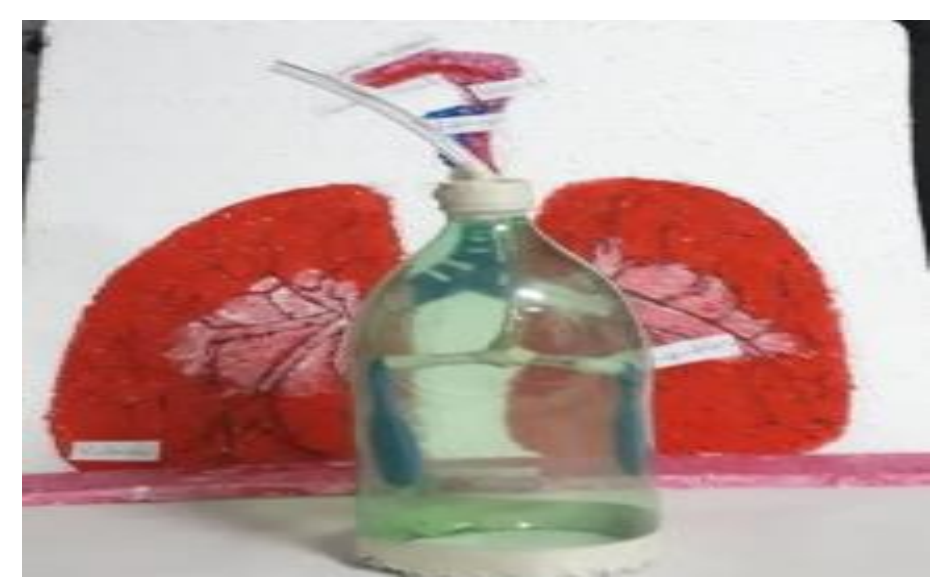

Fonte: Autoria própria.

Apesar de conhecermos todos os benefícios que a interdisciplinaridade traz no processo de ensino-aprendizagem, ainda encontramos resistência em sua utilização como método de ensino. Inicialmente, podemos destacar que a formação inicial dos professores que estão inseridos nas salas de aula traz consigo pouca informação a respeito de trabalho docente relativo ao uso da interdisciplinaridade como metodologia que pode auxiliar, em muito, o processo ensino-aprendizagem. Na realidade, o ensino interdisciplinar não tem avançado de maneira satisfatória no meio educacional, visto que o mesmo se depara com enormes entrelaçamentos, impedindo o seu desenvolvimento através de ações interdisciplinares por parte dos professores.

Segundo Santos (2012), as feiras de Ciências e mostras científicas investigativas representam uma estratégia pedagógica diferenciada das metodologias tradicionais, uma vez que são eventos em que os alunos são responsáveis pela comunicação de projetos planejados e executados por eles durante o ano letivo, além disso, se destacam por modificarem 
efetivamente o enfoque tradicional do ensino de Ciências nas escolas, propondo novas abordagens. Nesta perspectiva, as demonstrações científicas são compreendidas como possibilidade de promover uma integração entre aluno e professor, bem como entre escola e comunidade.

Diante do exposto, como terceira questão do questionário, tivemos como pergunta, “Os experimentos científicos apresentados ajudaram na sua formação?”, neste obteve-se o seguinte resultado apresentado no gráfico 4.

Gráfico 4 - Associação dos experimentos realizados na formação dos estudantes

\section{Os experimentos científicos apresentados ajudaram na sua formação?}

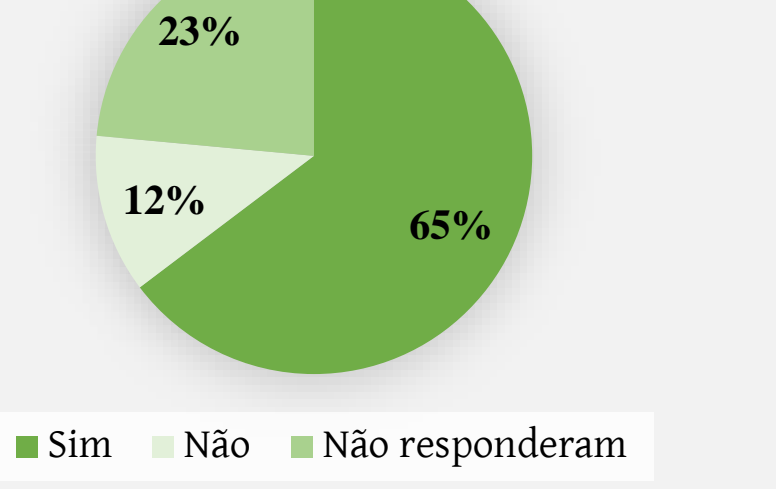

Fonte: Autoria própria.

Sendo assim, com base no gráfico 4, pode-se observar que os experimentos científicos apresentados na III Mostra do Saber, são muito relevantes no quis diz respeito a formação dos alunos, pois de acordo com os mesmos serve como base para auxiliar na escolha de uma futura profissão, despertando assim o interesse pela investigação científica, além de estimular o desenvolvimento do método científico, desenvolvimento de competências e habilidades relacionadas com o fazer científico, desenvolvimento do senso crítico, promovendo assim a interação comunidade-escola, percebendo então a importância da multidisciplinaridade no desenvolvimento da biologia. 
As feiras de Ciências podem contribuir para a socialização e troca de experiências no processo ensino-aprendizagem com a comunidade, possibilitando uma ampliação da visão de mundo dos participantes, expositores e visitantes da feira, permitindo a divulgação dos resultados de pesquisas, troca de experiências entre os pares, como forma de validação do conhecimento.

Atualmente, a educação necessita buscar alternativas de ensino-aprendizagem que motivem os alunos, que despertem seu interesse pelo aprender, desenvolvendo assim a habilidade da autonomia, evitando aula que somente repassa conhecimentos ou a escola que somente se define como socializadora de conhecimentos, não sai do ponto de partida e, na prática, atrapalha o aluno, porque o deixa acomodado. Sendo a feira de Ciências uma atividade pedagógica e cultural com um elevado potencial motivador do ensino e da prática científica, tanto no grupo de docentes quanto no grupo de discentes, a mesma possibilita o envolvimento de todos durante a organização do evento.

Nesse sentido, experimentos dessa natureza se fazem de fundamental importância, visto que facilita o processo de ensino-aprendizagem dos alunos no qual estes tenham e adquiram maior compreensão de um determinado conteúdo estudado em sala de aula, tornando-se de fácil assimilação (BRAGA et al., 2021).

\section{CONSIDERAÇÕES FINAIS}

Contudo, pode-se observar que a feira de Ciências é um momento único de conhecimento e criatividade realizado pelos alunos, pois é com estas atividades que se torna possível o trabalho da interação, criatividade e desenvolvimento das habilidades. Sendo assim, com o apoio dos estagiários do PIBID foi realizado alguns experimentos juntamente com os discentes da escola, voltados para os assuntos referentes à área da biologia trabalhada na sala de aula, para possível contextualização de conhecimentos já pré-estabelecidas.

Desde modo, foram desenvolvidos experimentos que envolviam DNA vegetal, Sistema Respiratório e Capilaridade, sendo estes assuntos explanados em sala de aula no decorrer do ano letivo. 
Assim com o auxílio do questionário aplicado no momento da feira, foi possível perceber em que nível a contextualização pode ser absorvida com sucesso pelos indivíduos que vivenciaram a exposição de conhecimentos, pois além de demonstrarem interesse pelo que foi oferecido na III Mostra do Saber, relataram que os conhecimentos explanados fizeram com que relembrassem conteúdos e assuntos trabalhados no ensino médio de forma diferenciada.

Por meio das demonstrações biológicas, tornou-se claro o envolvimento dos alunos nessas atividades, tal como os métodos científicos, conceitos e a explanação para a população, envolve uma construção de conhecimento científico com o conhecimento do cotidiano no espaço fora da sala de aula, onde através destas metodologias os alunos desenvolvem e aperfeiçoam seus conhecimentos e criatividades.

Por fim, pode-se perceber que o empenho e dedicação dos alunos são notórios, e se torna bem nítido ver a preocupação de buscar algo novo e chamativo para exposição. 0 espaço escolar nesses eventos se torna mais rico de conhecimento, e assim atrai diversos públicos. Sendo assim, pode-se concluir que a mostra de conhecimento é um meio muito satisfatório e proveitoso de achegar o aluno ao conhecimento, uma vez tendo participado deste evento e de certa forma medir a empolgação, interação, criatividade e esforço dos alunos através dos questionários aplicados.

\section{AGRADECIMENTOS}

A Coordenação de Aperfeiçoamento de Pessoal de Nível Superior (CAPES) pela concessão de bolsa de iniciação à docência (PIBID).

\section{REFERÊNCIAS}

BARROS, E.N.; SOUZA, E.J.S.; MACEDO, M. PIBID X ESCOLA PÚBLICA: uma parceria na melhoria da qualidade do ensino e da aprendizagem das séries iniciais do ensino fundamental. In: V Fórum Internacional de Pedagogia V FIPED, 2013, Vitória da Conquista-BA.

BRAGA, M.N.S.; PRESTES, C.F.; OLIVEIRA, V.G.; MENEZES, J.A.; CAVALCANTE, F.S.; LIMA, R.A. A importância das aulas práticas de química no processo de ensino-aprendizagem no PIBID. Diversitas Journal, v.6, n.2, p.25302542, 2021. 
BORBA, E. A importância do trabalho com Feiras e Clubes de ciências. Repensando o Ensino de Ciências. Caderno de Ação e Cultura Educativa. Vol. 03, coleção desenvolvimento circular. Secretaria de Estado de Educação de Minas Gerais, Belo Horizonte.

CAVALCANTE, F.S.; FREITAS, J.F.; COUTO, C.A.; TAVARES, G.S.B.; NOGUEIRA, P.G.; LIMA, R.A. DNA vegetal na sala de aula: o ensino-aprendizagem em botânica. Revista Ensino de Ciências e Humanidades - Cidadania, Diversidade e Bem Estar, v.1, n.1, p.176-191, 2018.

FARIAS, L.N. Feiras de Ciências como oportunidades de (re) construção do conhecimento pela pesquisa. 2006. 89f. Dissertação (Mestrado) - Núcleo Pedagógico de Apoio ao Desenvolvimento Científico, Universidade Federal do Pará, Belém, 2006.

FERNANDES, D.C.G.; ROCHA, S.G. Feira de ciências: contribuição no ensino-aprendizagem dos alunos de ensino médio. IV CONGRESSO NACIONAL DE EDUCAÇÃo, João Pessoa, 2017.

FREIRE, P. Pedagogia do Oprimido, Paz e Terra 17.ed. Rio de Janeiro, 1987.

HARTMANN, Â.M.; ZIMMERMANN, E. Feira de Ciências: A Interdisciplinaridade e a contextualização em produções de estudantes de ensino médio. VII Encontro Nacional de Pesquisa em Educação em Ciências. Florianópolis, p.01-12, 2009.

MANCINI, A. A. Aprendizagem significativa: a teoria de David Ausubel. São Paulo: Centauro, 2005.

MEZZARI, S.; FROTA, P.R.O.; MARTINS, M.C. Feiras multidisciplinares e o ensino de ciências. Revista Electrónica de Investigación y Docencia (REID), Número Monográfico, p.107-119, 2011.

ORMASTRONI, M.J.S. Manual de Feira de ciências. Brasília. CNPq, AED 30.

PELIZZARI, A.; KRIEGL M.L.; BARON M.P.; FINCK, N.T.L.; DOROCINSKI, S.I. Teoria da Aprendizagem Significativa Segundo Ausubel. Rev. PEC, v.2, n.1, p.37-42, 2002.

PEREIRA, A.B.; OAINGEN, E.R.; HENNIG, G. Feiras de Ciências. Canoas: Ulbra, 2000.

ROSA, P.R.S. Algumas questões relativas a feiras de ciências: para que serve e como devem ser organizadas. Caderno Brasileiro de Ensino de Física, v.12, n. 3, p. 223-228, 1995.

SANTOS, A.B. Feiras de Ciência: Um incentivo para desenvolvimento da cultura científica. Revista Ciência e Extensão, v.8, n.2, p.155-166, 2012.

VASCONCELOS, M.H.; FRANCISCO, W. Feira de ciências e ensino por projetos: uma experiência educativa no norte do Brasil. Acta Scientiae, v.17, n. 1, p. 235-251, 2015.

WANDERLEY, E.C. Feiras de Ciências Enquanto Espaço Pedagógico para Aprendizagens Múltiplas. In: Silvério Crestana. (Org.). Educação para a Ciência - Curso de treinamento em centro e museus de ciências. 1 ed. São Paulo: Editora livraria da Física, v.1, p. 269-274, 2001.

\section{$(\mathrm{cc}) \mathrm{EY}^{\mathrm{B}}$}

Este trabalho está licenciado com uma Licença Creative Commons - Atribuição 4.0 Internacional. 